doi http://dx.doi.org/10.18542/mri.v14i23.9580

\title{
FABRICAÇÕES DE GÊNERO NA AMAZÔNIA-BRASIL: ESTUDO DE CASO EM UMA ESCOLA PÚBLICA DE MANAUS-AM
}

\author{
GENDER MANUFACTURES IN AMAZON-BRAZIL: \\ A CASE STUDY AT A PUBLIC SCHOOL IN MANAUS-AM
}

Dielly de Castro SILVA ${ }^{1}$

Universidade Federal Rural da Amazônia (UFRA)

Jheime Matos de SOUSA ${ }^{2}$

Universidade Federal Rural da Amazônia (UFRA)

Mílton RIBEIRO

Universidade do Estado do Pará (UEPA) ${ }^{3}$

\begin{abstract}
Resumo: Este artigo tem como objetivo compreender as representações de gêneros de alunos do primeiro ano do ensino médio da Escola Estadual Márcio Nery, em Manaus-AM. O desenho metodológico da pesquisa envolveu observação direta e participante durantes as aulas, dinâmica em sala, exibição de uma produção audiovisual e entrevistas semiestruturadas com oito participantes deste primeiro momento, das quais selecionamos apenas quatro para análise. A partir da análise das entrevistas, observamos como as questões de gênero constituem formas de descrever os espaços e as experiências dos alunos, seja na família ou na escola.
\end{abstract}

Palavras-chave: Gênero, Representação, Escola, Família.

\begin{abstract}
This paper aims to understand the gender representations of first year high school students at Escola Estadual Márcio Nery, in Manaus-AM. The methodological design of the research involved direct observation and participant during classes, classroom dynamics, exhibition of an audiovisual production and semi-structured interviews with eight participants of this first moment, of which we selected only four for analysis. From the analysis of the interviews, we observed how gender issues constitute ways of describing the spaces and experiences of students, whether in the family or at school.
\end{abstract}

Keywords: Gender, Performance, School, Family.

\footnotetext{
${ }^{1}$ Técnica Administrativa na Universidade Federal Rural da Amazônia (UFRA). Especialista em Direitos Humanos e Diversidade em Educação pela Universidade Federal do Pará (UFPA). Licenciada e Bacharel em Ciências Sociais/UFPA. Graduanda em Direito/UFPA. E-mail: diellycastro@hotmail.com

${ }^{2}$ Mestranda em Educação no Instituto Federal do Pará (IFPA). Especialista em Educação em Direitos Humanos pela Universidade Federal do Pará (UFPA). Graduada em Letras - Português/UFPA. Professora da SEDUC-PA. Técnica na Universidade Federal Rural da Amazônia. E-mail: jheimemsousa@gmail.com

${ }^{3}$ Professor de Ciências Sociais na Universidade do Estado do Pará (UEPA). Doutorando em Antropologia no Programa de Pós-Graduação em Sociologia e Antropologia da Universidade Federal do Pará (UFPA). Editor da Revista Eletrônica Visagem e Editor Associado da Revista Novos Debates da Associação Brasileira de Antropologia (ABA).E-mail: $\underline{\text { millor_ufpa@hotmail.com }}$
} 


\section{INTRODUÇÃO}

Neste trabalho, propomos analisar as representações de gênero de um grupo de alunas/os de uma turma do primeiro ano do ensino médio, da Escola Pública Estadual Marcio Nery, em ManausAM. O nosso objetivo é compreender as interpretações que elas/es possuem acerca das relações de gênero e refletir sobre como essas relações ganham significados na vida cotidiana. Os eixos que orientam este trabalho circunscrevem a representação social, a escola e a família como pontos nodais de valoração e significação das experiências de gênero aqui compartilhadas. Esses dois últimos serão aqui analisados em vista de verificar quais papéis desempenham neste sistema de relações sociais. Adiantamos que, como instituições sociais, possuem o papel de reiterar e reproduzir as normas construídas socialmente a respeito de possuem o papel de reiterar e reproduzir as normas construídas socialmente a respeito de gênero, raça, classe e demais eixos de diferenciação social (BUTLER, 2003; BENTO, 2011); bem como fiscalizá-las e garantir sua manutenção, seguindo aqui as proposições de Foucault (2007).

A categoria analítica gênero será articulada neste texto a partir das considerações de Gayle Rubin (2017), que afirma que o gênero: “[...] é uma divisão de sexos imposta socialmente. Ele é um produto das relações sociais de sexualidade" (p. 31). Portanto, são nas interações entre os indivíduos que o gênero se processa, as hierarquias são construídas e os papéis de gênero são articulados. Portanto, as representações coletivas acerca do gênero podem ser entendidas como categorias construídas coletivamente pelas pessoas, que são reiteradas ao longo de nossa existência e experiência individual.

Adriana Piscitelli (2009) ao abordar a história do conceito de gênero enfatiza que a diferenciação entre sexo e gênero começou a ser pensada por Robert Stoller, em 1963, e, de acordo com este psicanalista, o sexo dizia respeito às distinções biológicas entre homens e mulheres enquanto o gênero fazia referência às características impostas culturalmente, podendo sofrer variações no tempo e no espaço, pois trata-se o gênero de uma construção no plano cultural. A ideia inovadora de Stoller alcançou impacto social apenas na década de 1970, quando as mulheres passaram a se organizar para requererem igualdade frente à dominação masculina.

E quando passaram a organizar os movimentos feministas, as mulheres se apropriaram da ideia de que a inferioridade a que estavam sendo historicamente subordinadas derivavam de construções sociais e não de distinções biológicas, uma vez que "é no âmbito das relações sociais que se constroem o gênero" (LOURO, 1997. p. 32). Sendo assim, passaram a questionar, a se opor e até subverter os padrões estabelecidos, aliando-se a toda uma produção teórica que vinha sendo desenvolvida por autoras nos anos 1930, 1950 e 1970, como: a antropóloga Margaret Mead (1901- 
1978), que "problematizou a ideia de que noções de feminilidade e masculinidade eram fixas, mostrando como variavam de uma cultura para outra" (PISCITELLI, 2009, p. 128); a filósofa Simone de Beauvoir (1908-1986), que estabelece o debate sobre a construção social da categoria mulher; e a também antropóloga Gayle Rubin (1949- ), que elaborou o conceito que chamou de sistema sexo/gênero, na obra intitulada "Tráfico de mulheres: notas sobre 'economia política' dos sexos", publicada em 1975, na qual estabelece que esse "é o conjunto de arranjos através dos quais uma sociedade transforma a sexualidade biológica em produtos da atividade humana" (PISCITELLI, 2009, p. 137).

A partir deste contexto é possível considerar que as questões de gênero (ou gênero como categoria de análise) se constituem como um movimento intelectual, prático e "[...] constitutivo de relações sociais baseadas nas diferenças percebidas entre os sexos e [...] (que) o gênero é uma forma primária de dar significado às relações de poder" (SCOTT, 1995, p. 86). Esse poder é qualificado pelo construto social e medido pelo pertencimento a um gênero tido como norma, o masculino; sendo o feminino detentor de poder difuso, em comparação ao seu oposto, com quem mantém, o mais das vezes, uma relação de dependência. Esta assimetria de poder favorece o homem em detrimento da mulher e dá origem a diversos tipos de violência, discriminação e desrespeito. Portanto, a igualdade de direitos, a distribuição e o exercício do poder são requeridos pelos movimentos feministas como forma de equilibrar a balança desfavorável às mulheres.

As teorias que tratam da distinção entre gênero e sexo/cultura e natureza, em suas vertentes essencialistas ou construcionistas, conformaram-se no interior dos movimentos feministas e geraram importantes conquistas para as mulheres, pois segundo Louro (1997, p. 35): “[...] essas são, muitas vezes, capazes de fazer dos espaços e instâncias de opressão, lugares de resistência e de exercício de poder". Contudo, a plenitude na equidade de gênero ainda não foi alcançada, configurando ainda um longo caminho.

Ademais, os estudos sobre gênero discutem a desconstrução dos modelos de masculinidades e feminilidades fruto da cultura a que estamos submetidas/os, bem como a compreensão da diversidade de gênero. $\mathrm{O}$ sistema binário homem/mulher não satisfaz a diversidade humana com seus arranjos que incluem variadas experiências e performances de gênero, como: transexuais, travestis, crossdresser, andróginos, agêneras, pessoas não-binárias e afins. Tão pouco as doutrinas religiosas ou convicções filosóficas conseguem responder de maneira adequada as essas questões sem desvirtuamento ideológico problemático. 
Abrindo parênteses nesta introdução, destacamos que nenhuma convicção política, filosófica, religiosa, ou mesmo quaisquer sensos de moralidade, podem servir de base para violação de direitos ou supressão da dignidade, inerente a todos os seres humanos, como preconizados na Declaração Universal dos Direitos Humanos, Artigo $1^{\circ}$, de 1948. A história da humanidade mostra que, por causa de convicções de naturezas variadas, como as ideologias totalitárias, seres humanos foram submetidos a tratamentos sub-humanos, degradantes e lastimáveis.

As representações sociais, coletivas e naturalizadas, exercem o poder de conformar comportamentos e ações no mundo sensível. No entanto, apesar das vigências de gênero determinarem caminhos exclusivos sobre os quais deveremos seguir, as imposições não se realizam por completo; havendo frestas nesse sistema; ajudando assim a dinamizar as regulações e o poder. No entanto, esta dinâmica acaba por oprimir meninas e meninos que não reiteram em seu modo de ser as características demarcadas de maneira rigorosa para homens e mulheres em nossa sociedade; e um caminho delicado é evitar que isso ocorra e se propague dentro do espaço escolar.

Assim, a escola, como uma das instituições sociais responsáveis pela socialização dos indivíduos, poderia representar o espaço ideal para favorecer a igualdade e o respeito por abrigar a diversidade, constituindo-se em um modelo no qual indivíduos deveriam praticar a convivência pacífica com o diverso, sendo estimulados a partir de discussões e reflexões, a respeitar e compreender o outro.

No entanto, o conceito de escola aqui é trabalhado sob a perspectiva de Foucault (2007), que nos afirma que este é um espaço disciplinador onde se vigiam as/os sujeitas/os-alunas/os a fim de que os padrões e normas continuem vigorando e não sejam subvertidos. E mais, em casos de violações das normas, a punição é aplicada, cumprindo-se aí uma finalidade muito mais reguladora do que simplesmente produtora, mediadora e difusora do saber.

O que se observa nas escolas é o silenciamento em temas propícios ao conhecimento da diversidade humana, como gênero, por exemplo. O silêncio gera a perpetuação de culturas que desfavorecem o pluralismo, a democracia e a convivência pacífica entre as pessoas. A diversidade que está na cidade e no campo, nas ruas e nas casas, nos centros urbanos e nas periferias transita também pelo centro de conhecimento formal que é a escola. O transitar de vidas e pessoas diversas, aprendendo, conhecendo, descobrindo sobre as ciências propicia o desenlace de temas e questões, reflexões e questionamentos, muito embora as/os gestoras/es e equipe docente das escolas retratem as relações sociais como sendo uniformes e todas iguais, sem variações ou lições a serem aprendidas. Por isso, enfatizamos que é necessário compreender a extensão do pensamento dessas/es sujeitas/osalunas/os sobre gênero e entender quais as referências dessas ideias para que assim seja possível 
pensar em maneiras de abordar o tema em sala, objetivando a desconstrução de preconceitos e discriminação originados das relações de gênero.

Em termos de desenho metodológico, a pesquisa foi realizada na Escola Estadual Márcio Nery, em Manaus-AM. Os dados apresentados aqui foram coletados por meio de entrevista semiestruturadas, constando de um primeiro momento com aula introdutória na disciplina de Sociologia e exibição de um material audiovisual intitulado "Gênero nas Escolas", produzido por Lorelay Fox, uma drag queen que possui um canal no YouTube chamado "Para Tudo". No vídeo, de aproximadamente quatro minutos, de uma maneira bastante didática, Lorelay explica o que é gênero e destaca a importância de discutir esse tema no ambiente escolar. Esse momento de preparação ocorreu em uma aula apenas e serviu como ponte para explorar a temática durante as entrevistas. $\mathrm{O}$ público-alvo foram alunas/os do primeiro ano do ensino médio, uma vez que a temática aqui abordada se encontrava fundamentada nas Diretrizes Curriculares Nacional e na Proposta Curricular do Ensino Médio - Sociologia, do Estado do Amazonas, em 2016. No entanto, atualmente, o ensino médio brasileiro é regulamentado pela Resolução CNE/CP n. 4, de 17 de dezembro de 2018, que instituiu a Base Nacional Curricular Comum na etapa do Ensino Médio (BNCC-EM) e fez desaparecer as palavras gênero e sexualidade de seu texto final. No documento que regulamenta o Ensino Médio no Amazonas, o conteúdo "Gênero e Diversidade" propunha-se que as/os alunas/os alcançassem a competência de: "Analisar e compreender as condições possibilitadoras da emergência de novos gêneros [...], de modo a ressaltar a diversidade"; desenvolvam a habilidade de "Identificar a emergência de novos gêneros" (p. 4).

Após esta breve apresentação, apontamos que o presente artigo está organizado em três seções, a saber: a primeira seção é sobre as dimensões metodológicas da pesquisa de campo, na qual abordamos sob quais circunstâncias ocorreu a apresentação do vídeo descrito acima em sala, seguido por uma breve descrição sobre este momento introdutório, o andamento da aula e a reação das/os alunas/os durante essa exibição; na segunda seção, abordaremos a relação com a famílias e as percepções das/os jovens alunas/os sobre essa instituição social; por fim, na última seção, analisaremos como a escola pode ser entendida com um espaço de reprodução das normas gênero. Outrossim, entendemos e destacamos que o tema das relações de gênero expande-se para além do binarismo homem/mulher e apontamos para a urgência em falar sobre gênero e identidades sexuais em ambientes escolares. Contudo, neste artigo, detemo-nos em analisar e compreender apenas o duplo feminino/masculino e os papéis de gênero desempenhados por cada uma dessas pessoas em relação, como preconizado por Scott (1995). 


\section{QUANDO O CAMPO É A ESCOLA: QUESTÕES DE MÉTODO}

Manaus é a capital do estado do Amazonas, um espaço com área de 11.401,092 km², o que corresponde a dez vezes o tamanho da cidade de Belém-PA, cidade de nascimento das/os autoras/es desse artigo. Desde o Decreto Municipal n. 2924, de 07 de agosto de 1995, a região metropolitana encontra-se dividida em sete zonas, a saber: Zona Sul, Zona Norte, Zona Oeste, Zona Leste, Zona Centro- Oeste, Zona Centro Sul e Zona Rural. A Zona Sul é considerada a mais elitizada da cidade, está localizada próxima à área central da capita e situam-se nela a Universidade Estadual do Amazonas, o Instituto Federal do Amazonas, Fundação Alfredo da Matta - centro de referência nacional e internacional no tratamento de Hanseníase e dermatologia tropical - e o Teatro Amazonas

- um dos equipamentos fundamentais na constituição do centro histórico de Manaus. Por esses motivos, a Zona Sul é considerada um bairro nobre, uma área cara para algumas/ns moradoras/es da cidade.

Nosso campo de pesquisa situou-se na escola Márcio Nery, localizada no limite entre dois bairros da Zona Sul, São Francisco e Cachoeirinha. Apesar de ser uma área considerada nobre, alguns bairros da Zona Sul figuram, nos meios de comunicação, como bairros com índices altos de tráfico de drogas, como é o caso do São Francisco. Por conta deste fato, em 2015, a escola deixou de funcionar no turno da noite, devido à incidência de tráfico nas proximidades, que colocava em risco a segurança de toda a comunidade escolar. Atualmente, a Escola Estadual Marcio Nery funciona apenas no turno matutino e vespertino, possui quatorze turmas, sendo quatro de primeiro ano do ensino médio, cinco de segundo e cinco de terceiro ano. Ela atende, em grande parte, um quantitativo de 1.228 alunas/os regularmente matriculadas/os. De acordo com o setor pedagógico, uma pequena parte dessas/es alunas/os é proveniente de bairros próximos, como Praça 14, Petrópolis, São Jorge e Raiz, e a maior parte são dos dois bairros que dividem a escola, Cachoeirinha e São Francisco; sendo este último bastante conhecido pela presença do tráfico de drogas ilícitas e de altos índices de violência.

A escola convive com esses problemas sociais e vem criando algumas ações de enfrentamento, ainda que sem o apoio da Secretaria de Educação local, como é o caso do Dia D, que ocorre uma vez a cada semestre. Neste dia, as/os alunas/os, professoras/es, mães, pais e/ou responsáveis pelas/os jovens participam de campanhas preventivas contra o uso de drogas. As feiras bimestrais também constituem uma forma de a escola buscar aproximação com a comunidade: a primeira do ano a ser realizada é a Feira de Humanas, no mês de abril; a Feira Literária ocorre em junho; a Feira de 
BioExatas em setembro; e, por fim, os jogos estudantis e comunitários. Nesta ocasião, as/os próprias/os alunas/os, sob a orientação das/os professoras/es de cada uma dessas áreas, produzem os trabalhos referentes aos temas de cada feira e se responsabilizam por divulgar o evento nas imediações da escola. Esta programação foi desenhada no Projeto Político Pedagógico (PPP) como uma forma de integração da escola com a comunidade. As feiras ocorrem há três anos e tem conseguido alcançar o objetivo a que se propõe, de acordo com a direção; e a presença da comunidade tem sido significativa.

Na busca de inserção das mães, dos pais e/ou das/os responsáveis no cotidiano escolar das/os alunas/os, o projeto político da E. E. Márcio Nery incluiu em suas atividades ordinárias a apresentação do Projeto de Lei Suplementar n. 620/2011, aprovado na Câmara dos Deputados do Estado do Amazonas, que permite a ausência do trabalhador para comparecimento às reuniões escolares das/os filhas/os desde que apresente comprovante de comparecimento à escola. Assim, antes das reuniões, as/os professoras/es são orientadas/os a explicar em sala de aula o conteúdo deste projeto de lei a fim de garantir a presença dos pais nas reuniões sobre o desempenho escolar das/os alunas/os. Infelizmente, esta ação ainda não teve um resultado satisfatório, pois é possível observar nas listas de frequência das reuniões uma participação de mães, pais e/ou responsáveis muito inferior a de alunas/os que a escola possui.

O quadro de docentes da escola é composto por trinta professoras/es. E integra, ainda, a comunidade escolar um diretor, um pedagogo, duas secretárias, um porteiro, quatro auxiliares de cozinha, duas pessoas responsáveis pelos serviços gerais, uma bibliotecária -função que é exercida por uma das professoras em tempo vago.

A estrutura física da escola é composta por 14 salas de aula, uma sala das/os professoras/es, uma sala destinada à Hora de Trabalho Pedagógico (HTP), uma biblioteca (que funciona em períodos específicos já que não tem ainda um/a funcionária/o destinada/o exclusivamente para esta função), uma quadra de esportes, quatro banheiros, um laboratório de ciências e um auditório (que ainda se encontrava em construção em 2016).

A pesquisa foi realizada exclusivamente com alunas/os do turno da manhã, de uma turma pertencente ao primeiro ano do ensino médio. A turma contém um total de quarenta pessoas matriculadas; deste total, oito participaram das entrevistas. Optamos por selecionar quatro das entrevistas para compor este trabalho, levando-se em conta o tempo destinado à produção deste artigo.

A turma do primeiro ano foi escolhida porque o conteúdo "Diversidade de Gênero" faz parte do Programa Curricular de Sociologia, portanto, a temática trabalhada em sala constituiu a 
oportunidade ideal de realização deste trabalho junto desta turma. Antes de participarem da entrevista, as/os alunas/os assistiram a uma aula introdutória relativa ao conteúdo supracitado, como explicado em parágrafos anteriores.

$\mathrm{Na}$ etapa de elaboração do plano de aula, recorremos à metodologia utilizada no "Módulo IV: Diversidade: Políticas Públicas, Escola e Sociedade I - Gênero", do Curso de Especialização em Educação em Direitos Humanos e Diversidade (EDHDI) da Universidade Federal do Pará, coordenado pela Profa. Dra. Marlene Freitas nos anos de 2015-2016; as duas coautoras deste trabalho foram alunas deste curso. Em uma das aulas deste módulo, o professor que assina a coautoria deste texto iniciou a aula realizando uma breve dinâmica: traçando uma linha vertical, dividindo o quadro ao meio, escreveu em um dos lados, no topo do quadro, a palavra "mulher"; e no outro lado a palavra “homem”. Após uma pequena intervenção sobre a forma como conduziríamos a dinâmica, foi-nos pedido que de um lado ditássemos de forma espontânea palavras (substantivas ou adjetivas) que representassem o termo "mulher" e "homem". Para surpresa da turma, aquele exercício demonstrou que nós não estávamos livres de reiterar as normas, estereótipos e convenções de gênero presentes em nossa sociedade: o espanto foi tanto que percebemos que a palavra "vulgar" é mais utilizada para referir-se às mulheres que aos homens, por exemplo.

Esta simples atividade tornou-se complexa à medida que deslocou os nossos olhares em direção às situações que naturalizam os lugares de subordinação das mulheres; levando à percepção do alcance que essas definições possuem ao aprisionar todas/os nós; e reconhecer a urgência de contribuirmos para a desconstrução dessas definições essencializadas. Na reconstrução desse exercício na turma do primeiro ano na E. E. Márcio Nery, tivemos o seguinte resultado:

\section{QUADRO 1: JOGO DE GÊNERO}

\begin{tabular}{|c|c|}
\hline MENINA & MENINO \\
\hline $\begin{array}{l}\text { BONECA, VIDEOGAME, FLORES, } \\
\text { DELICADA, FOGÃO, AMIGA, PARCEIRA, } \\
\text { BALÉ, MENINO, SENSÍVEL, ATITUDE, } \\
\text { MAQUIAGEM, ROSA, CHOCOLATE, } \\
\text { COLAR, BOLSA DA MORANGUINHO, } \\
\text { PACIENTE, BARBIE, COMPREENSÍVEL, } \\
\text { CALCINHA, NOVELA, METIDA, COME. }\end{array}$ & $\begin{array}{l}\text { FUTEBOL, VÍDEOGAME, BRUTO, } \\
\text { CARRO, GOSTOSO, MENINA, PACIENTE, } \\
\text { PERSONALIDADE FORTE, CABELO CURTO, } \\
\text { AZUL, LASANHA, CORDÃO, ALPERCATA } \\
\text { DO SENINHA, } \\
\text { INCOMPREENSÍVEL, CUECA, SKATE, } \\
\text { PAGA (A CONTA) }\end{array}$ \\
\hline
\end{tabular}

Fonte: Pesquisa de Campo, 2016. 
Após a dinâmica em sala e elencadas as palavras (substantivas e adjetivas) associadas às representações sobre meninas e meninos, elas/es foram questionadas/os sobre a possibilidade de inversão daquela ordem; se aceitariam que as palavras usadas para definir os meninos fossem usadas para descrever as meninas e vice-versa. Como demonstrado abaixo:

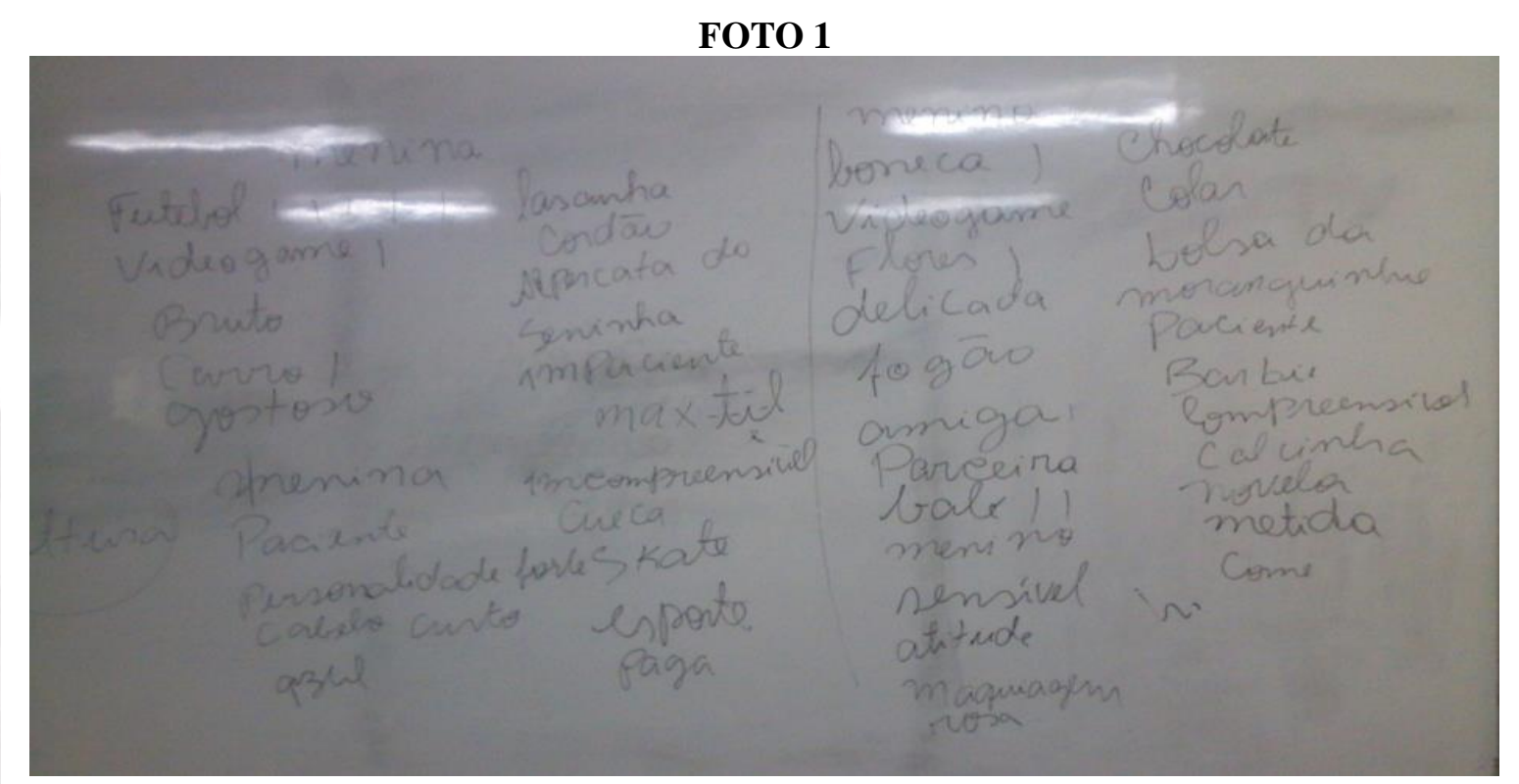

Fonte: Dielly Castro, 2016.

O questionamento gerou uma discussão: algumas/ns alunas/os disseram não ver problemas em "videogames" e "carros" serem permitidos às meninas; outras/os reagiram à "maquiagem", "balé" e "bonecas" serem permitidos aos meninos. Esta inversão constitui-se como problemática porque ataca o sistema binário rígido homem/mulher: o qual não permite que homens adentrem os espaços determinados como feminino, pois isto significaria deixar de ser homem. O homem, definido como a norma em diversos sistemas sociais, políticos e econômico, deve conservar sua masculinidade e não maculá-la com práticas atribuídas às mulheres - consideradas como inferiores, na maioria das vezes. Portanto, não é admissível a brincadeira de bonecas entre os meninos.

A construção desta hierarquia em consonância com os modelos de masculinidades inviabiliza a aceitação de meninos com práticas ditas afeminadas, como afirma Scott (1995, p. 82): “[...] A ideia de masculinidade repousa na repressão necessária de aspectos femininos - do potencial do sujeito para a bissexualidade - e introduz o conflito na oposição entre o masculino e o feminino”. Por isso, brincar de boneca não pode, de forma alguma, ser concebida como atividade desenvolvida pelos meninos.

Ademais, há uma prescrição de gênero, no sentido de ser somente homem ou mulher, ou encontrar-se circunscrito apenas às regras atribuídas a um ou outro (nunca aos dois!); não sendo 
permitido maneirismos e atitudes lidos femininos em homens e vice-versa; isto porque a identidade de gênero em seu sentido classificatório antagônico rígido exclui as semelhanças naturais compartilhadas por homens e mulheres, como afirma Rubin (2017):

Longe de ser uma expressão de diferenças naturais, a identidade de gênero exclusiva é a supressão de semelhanças naturais. E isso demanda repressão: nos homens, do que quer que seja a versão local de traços "femininos"; nas mulheres, do que quer que seja a versão local de traços "masculinos". A divisão dos sexos tem como efeito reprimir certas características de personalidade de praticamente todas as pessoas, homens e mulheres. Este é o sistema social que oprime as mulheres nas relações de troca nele vigente, e que oprime a todos com sua insistência em uma divisão rígida de personalidade (p. 31-32).

Em se tratando da brincadeira com bonecas, esta atividade está ligada ao incentivo e ao treinamento do saber-cuidar, uma vez que é disseminada a ideia de que apenas as mulheres cisgênero são capazes de conceber outro ser humano. Então, podemos pensar (e a sociedade ratifica isto) que, baseado nesta capacidade, as mulheres nascem para serem mães e por isso precisam aprender o cuidado. Porém, o cuidado também deveria ser uma habilidade desenvolvida pelo homem, visto que também é parte essencial na concepção moderna de indivíduo.

Portando, podemos enquadrar neste sentido as semelhanças naturais entre homens e mulheres em termos fisiológicos e reprodutivos, pois a união sexual entre um homem e uma mulher é que produz um ser humano, portanto, ambos devem desenvolver habilidades em relação ao cuidado. Entretanto, não há viabilidade neste pensamento já que a oposição/binaridade é impositiva em todas as situações e formas. Como corolário, a brincadeira de boneca é somente para meninas.

A ideia de atribuir o cuidado à mulher, baseada em disposições biológicas, contrapõe-se às teorias de gênero de caráter construtivista, uma vez que os estudos evidenciam que justamente desconstruir a visão naturalizada que determina os papéis das mulheres na sociedade é o vetor que dá impulso às políticas de gênero. Na famosa frase "Ninguém nasce mulher: torna-se mulher", Beauvoir (1967) nos apresenta a ideia de gênero como construção social e prossegue: "Nenhum destino biológico, psíquico, econômico define a forma que a fêmea humana assume no seio da sociedade; é o conjunto da civilização que elabora esse produto intermediário entre o macho e o castrado que qualificam de feminino. Somente a mediação de outrem pode constituir um indivíduo como um outro." (p. 9).

Esta é uma provocação das certezas do gênero enquanto essência porque somos levadas/os a repensar todo um ciclo de aprendizado e passamos a questionar a construção sociocultural que nos enquadrou como pessoas de determinado gênero. Assim, apareceu como conflitante para algumas meninas e meninos da turma perceberem que palavras e objetos sobre os quais elas/es aprenderam a 
enxergar exclusivamente como femininos ou masculinos agora poderiam pertencer a ambos os gêneros.

Após a livre exposição dos argumentos, a aula seguiu com uma breve explicação sobre como essas diferenças operam no plano sociocultural, bem como se articulam no plano das representações e do imaginário social. Não podemos deixar de mencionar aqui o quanto este assunto mobilizou a turma. As/Os alunas/os demonstraram-se interessadas/os em expor suas ideias, em debater a temática e, durante a exposição, aqueles olhares reflexivos poderiam facilmente ser igualados aos olhares das/os alunas/os da EDHDI; posto que ambas as turmas foram levadas a experimentar o questionamento acerca das regulações de gênero.

Com o final da explicação, as/os alunas/os assistiram ao vídeo intitulado "Gênero nas Escolas", que compõe o canal "Para Tudo", no YouTube. Nele, a drag queen Lorelay Fox, interpretada pelo publicitário Danilo Dabague, explica de forma bastante didática a importância das abordagens de gênero nas escolas. Partindo de uma experiência vivenciada durante a infância, na qual recebeu da professora a orientação de brincar apenas com meninos, a apresentadora reafirma a prerrogativa de tratar as questões de gênero nas escolas como Direitos Humanos e problematiza ainda a atuação da escola que por vezes reforça as normas de gênero.

Após a exibição do vídeo, à primeira reação da turma, coube a seguinte pergunta: "Isso é homem ou mulher, professora?". Como resposta, provocamos com outro questionamento: “O que é ser homem e o que é ser mulher para vocês?”. Seguiu-se o silêncio. Por fim, uma outra pergunta foi lançada: "Com base no quadro que vocês construíram, na imagem de Lorelay e na as características que vocês utilizaram para compor esse quadro, podemos definir o que é ser menino e o que é ser menina?”. A resposta foi uníssona: "Não!”.

Após essa aula introdutória, com o objetivo de cumprir as metas deste trabalho e para nos aprofundarmos nas representações que estas/es alunas/os possuiam sobre gênero, realizamos entrevistas semiestruturadas com alguns alunos da escola E. E. Marcio Nery. Os critérios utilizados para selecionar as/os participantes dessa etapa da pesquisa foram, cumulativamente, terem participado da aula introdutória sobre gênero ministrada na turma do primeiro ano da Escola Marcio Nery e terem irmãs/ãos. Este último critério fora estabelecido ainda durante a construção da pesquisa e na etapa de elaboração das perguntas que iriam compor a entrevista semiestruturada, pois no nosso entendimento

\footnotetext{
${ }^{4}$ Disponível em: https://www.youtube.com/watch?v=ZIJ2Ifu6SIM
} 
seria mais simples para as/os alunas/os que tivessem irmãs/ãos identificarem as possíveis diferenças na criação e na relação familiar, caso estas se fizessem presentes.

Nas entrevistas, procuramos basicamente conhecer um pouco do cotidiano das/os alunas/os em casa e na escola, extraindo elementos de seu convívio social com as mães, pais, irmãs/ãos e colegas da escola com a intenção de identificar como as relações de gênero constituem esses espaços. Para ter acesso mais direto à representação de gênero construída por esses alunos, eles foram questionados sobre o que é ser menino e o que é ser menina. As conversas foram realizadas na escola, durante os momentos nos quais os alunos encontravam-se sem aula ou qualquer atividade escolar.

\section{QUESTÕES DE GÊNERO NA FAMÍLIA: FABRICANDO MENINAS E MENINOS}

As diferenças em relação ao gênero manifestam-se no convívio familiar, na criação das/os filhas/os, no modo de tratar meninas e meninos dentro de casa e nas formas como se expressam os modelos de masculinidade ou feminilidade no espaço público. Neste sentido, as quatro pessoas que participaram desta pesquisa possuem irmãs e irmãos e todas foram unânimes em afirmar que existe diferença na criação de mulheres e homens.

Mayara, 16 anos, tem três irmãs e irmãos e afirma que a diferença está na liberdade que o irmão homem possui. A liberdade pensada por ela diz respeito a ter permissão da mãe e do pai para sair sozinha de casa. Ela sente que seu acesso ao espaço público, por exemplo, é mais limitado que o de seu irmão Max, como demonstra o trecho da entrevista abaixo:

Pesquisadoras/es: Então... você e o Max são criados da mesma forma? Têm as mesmas responsabilidades?

Mayara: Nas coisas de casa sim, mas de sair não. O Max sempre sai com os colegas dele na rua, mas pra sair eu tenho que pedir pra minha amiga ou pra mãe da minha amiga ligar pra mamãe pra ela poder deixar eu ir.

Pesquisadoras/es: Mas isso é preocupação da sua mãe, né?!

Mayara: E por que ela não faz o mesmo com ele? Se eu demoro ela vai atrás de mim e eu chego em casa e ela faz gritaria, mas com ele não... o Max pode até dormir na rua (risos).

A liberdade também aparece ainda como marcador da diferença na criação de meninas e meninos na conversa que tivemos com mais dois entrevistados. Gabriel, 15 anos, tem uma irmã de 10 anos, e quando questionado sobre o que significava ser menina e ser menino, ele responde:

Pesquisadoras/es: O que é ser menino e o que é ser menina pra ti?

Gabriel: Bom... eu não sei lhe dizer como é ser menina, mas minha vida comparada com a de menina é bem mais livre; de ter muitos amigos... pra mulher é tipo mais fechado... mais presa... não que ela não pode fazer um monte de coisa; ela pode, mas é mais difícil. 
Elisa, 15 anos, possui dois irmãos e, assim como Mayara, ressalta que uma das diferenças de criação entre ela e os irmãos, é a liberdade de sair:

Pesquisadoras/es: Que outras diferenças você percebe na criação de vocês?

Elisa: Tem a questão de sair. Eles podem sair mais que a gente. A mamãe sempre diz que a gente não tem que ficar andando pela rua.

Pesquisadoras/es: Tu concordas com ela?

Elisa: Por uma parte sim, mas por outra não... os meninos também não deveriam ficar muito na rua, [pois] acontece um monte de coisas não só com as meninas, com os meninos também.

Uma possível análise desses trechos recortados de entrevistas, e da concepção das/os entrevistadas/os sobre a liberdade, nos leva inevitavelmente a recorrer ao uso das categorias casa e rua para problematizar a relação que se constitui como um dilema brasileiro: a relação entre o público e privado. O antropólogo Roberto DaMatta (1997) define a rua como espaço da malandragem, do perigo e da sujeira; um espaço sem regras, no qual se pode fazer de tudo - o lugar da objetividade da burocracia. Como contraponto, temos a casa como uma categoria oposta, pois este seria o espaço dos códigos morais, um espaço protegido, possuidor de regras determinadas (pelo patriarca) e específicas - o lugar da subjetividade da família. Não fazemos em casa aquilo que fazemos na rua, ou seja, se lá foram não existem regras, dentro de casa você deverá seguir algumas.

E nas falas de nossas/os entrevistadas/os percebemos que as práticas de socialização que constroem a identidade em meninos são tecidas com mais facilidade em espaços públicos; ao passo que entre as meninas a fabricação de gênero está associada ao âmbito privado; é perceptível ainda que a socialização das meninas no espaço público recebe mais a vigilância de mães, pais e da família que a dos meninos.

Entender a liberdade a partir desse ponto de vista nos leva a algumas conclusões importantes, como as observadas pela entrevistada Elisa: a rua oferece perigo tanto para os meninos quanto para as meninas. Porém, enquanto protegemos as meninas no ambiente seguro da casa, com regras morais bem definidas e circunscrevendo suas formas de trânsito entre os espaços públicos e privados, continuamos enviando nossos meninos para os perigos e a desordem que habitam na rua.

Uma outra explicação para as meninas conformarem-se ao espaço doméstico estaria na capacidade de engravidar e, consequentemente, desenvolver a maternidade. As relações sociais que organizam as famílias priorizam a mulher no espaço privado do lar, tendo em vista a naturalização da condição maternal. E disso decorrem as outras formas de inserção da mulher na experiência do cuidado, como a responsabilidade de cuidar da casa e da família. A diferença biológica entre homens e mulheres orienta os papéis de gênero e situa, desde a infância, a mulher no espaço doméstico, como afirma Piscitelli (2009): 
Em muitos cenários, a vinculação entre qualidades femininas e a capacidade de conceber filhos e dar à luz contribui para que a principal atividade atribuída às mulheres seja a maternidade, e que o espaço doméstico e familiar seja visto como seu principal local de atuação. (p. 118).

Por outro lado, a sociedade segue reiterando a existência de espaços sociais definidos para meninas e meninos e condicionam uma assimetria na maneira como se olha para aquelas: meninas que estão na rua não devem ser tratadas como as meninas que estão em casa, sendo as primeiras menos dignas de respeito. De forma similar operam as circunstâncias acerca de um menino que prefere ficar dentro de casa ao invés de sair com os amigos; ele não será encarado como homem o suficiente.

Um outro caminho apontado pelas entrevistas diz respeito aos afazeres domésticos. Estes são direcionados sempre às meninas, uma vez que elas são criadas para ser donas de casa ou, no mínimo, expertises no manejo do saber-cuidar. Trata-se da construção de seres capazes de cuidar e para isso torna-se imprescindível as habilidades nos afazeres domésticos porque o cuidado parte do âmbito familiar para o espaço público.

O historiador Philippe Ariès (1986) narra como a criança era vista no século XVII, momento no qual a educação era monopólio do sexo masculino e as crianças do sexo feminino eram criadas para serem excelentes donas de casa, habilidosas nas atividades domésticas. Quando comparamos com tempos atuais, observamos que as mulheres adquiriram o direito à educação, no entanto, o treino para ser do lar persiste em comparação à criação dos meninos. Assim, é possível observar na fala de Elisa quando considera que uma das diferenças entre ela e o irmão é a realização das tarefas domésticas:

Pesquisadoras/es: Tu consegues perceber alguma diferença na criação que tu e tua irmã tiveram com a criação que os teus irmãos tiveram?

Elisa: Sim! Tem muita diferença.

Pesquisadoras/es: Tipo, quais?

Elisa: Assim... a gente sempre teve que fazer os trabalhos da casa, e eles (os irmãos) nem sempre tem que fazer.

Os trabalhos domésticos se estendem por toda a vida das mulheres, resultando em duplas (e até triplas) jornadas no período do emprego formal, com as atividades remuneradas. Então, não importa quão cansada esteja, pois quando há um homem e uma mulher dividindo os mesmos ambientes, esta sempre vai arcar com a obrigação de trabalhar dentro e fora de casa, realizando as tarefas de organização e manutenção do espaço doméstico. A dupla (ou tripla) jornada é realidade e explicita a divisão de tarefas advindas da diferença entre os sexos. $\mathrm{O}$ homem não precisa desempenhar 
esta dupla jornada nos casos em que trabalha fora, pois culturalmente o homem é apenas o provedor, aquele que sustenta o lar.

Ainda que haja lares nos quais as mulheres são criadas sem precisar aprender atividades domésticas - como lavar, passar e cozinhar - a sociedade se encarrega de questionar estas mulheres do porquê de elas não estarem desempenhando seus papéis de mulheres. A cobrança é explícita quando uma mulher afirma não saber cozinhar. Isto soa para muitas pessoas como uma ofensa às relações e normas que estabeleceram a divisão de tarefas baseadas no sistema sexo/gênero.

Como aponta Piscitelli (2009), em uma pesquisa realizada em 2001, a Fundação Perseu constatou que 96\% das entrevistadas (de um espaço amostral de 2.502 entrevistas) "cuidavam das tarefas domésticas e das crianças, mesmo que também trabalhassem fora de casa. Nos casos em que o trabalho doméstico era dividido com outra pessoa, em quase a metade dessas situações dividiamno com outra mulher, geralmente a mãe ou as filhas" (p. 121). Mais um exemplo de como as mulheres ainda figuram como elementos centrais no que diz respeito aos afazeres domésticos.

Estes fatos, em consonância com nossa pesquisa, revelam que as meninas são obrigadas a lavar, passar e cozinhar por imposições relacionadas ao gênero, por uma divisão baseada na essência da condição feminina e as origens disto adviriam de sua capacidade natural de gerar filhos, frutos de uma concepção essencialista das relações sociais. São diferenças entre homens e mulheres tendo como critério corpos que podem (ou não) gerar vidas.

Analisamos também nos discursos das/os entrevistadas/os que o gênero feminino é visto como alguém que sempre é descrito como comportada, regrada nos modos e aquela que não viola normas. A submissão tem de ser parte de sua personalidade. O espírito "baderneiro" caberia aos meninos, aos quais são permitidos violar regras, subverter ordens e ultrapassar os limites, que são vistos como desafios a serem superados, como no trecho: Mayara: os meninos falam mais e levam tudo na brincadeira e todo mundo acha legal, mas
a menina não, tem que sempre fazer as coisas direitinho, e sempre não pode errar (grifo
nosso).

Gabriel: Ah, ela sempre tem ajuda pra fazer as coisas, eu e meu irmão não, e ela sempre se comporta melhor e todo mundo fica falando dela (grifo nosso).

"Fazer as coisas direitinho" e "sempre se comportar melhor" significam fazer coisas de menina ou agir como uma menina. A pergunta surge tão logo as evidências afloram: ser comportada é coisa de menina mesmo? É uma habilidade ou característica inata pelas quais são responsáveis os cromossomos XX? Ou foi alguém que determinou que devria ser assim? De outra forma, a falta de 
comportamento adequado é uma característica própria dos meninos? É uma característica presente nos cromossomos XY? Por certo que não.

A antropóloga Margaret Mead afirma que os traços de caráter, como o comportamento (adequado ou não), são aprendidos desde que a criança nasce (PISCITELLI, 2009, p. 129). Ou seja, são aprendidos e não inatos ou próprios de uma criança do sexo feminino ou masculino. E isso levanos a crer que o comportamento regrado de uma menina não é responsabilidade do condicionamento biológico e sim uma construção social, uma demarcação de caráter engendrada nas (e pelas) interações sociais. Um menino pode ser mais contido em suas atitudes do que uma menina, pode seguir regras, ser obediente e outras coisas consideradas femininas e isso não deve ser pensando como uma perca de suas características masculinas.

A forma como criamos meninas e meninos segue o caminho da naturalização das diferenças baseadas nos corpos sexuados, na representação determinada pelos órgãos geniais. Logo, um menino comportado demais é criticado e uma menina não-comportada é criticada da mesma forma e tudo isso porque as características morais que as/os diferenciam precisam respeitar os códigos de conduta: existem coisas de menino e coisas de menina. Isso aparece como algo inventado e construído nas relações sociais que se tornam verdade absoluta tão logo reiterado por todas/os.

A seguir, resumimos as contraposições apresentadas, direta ou indiretamente, nos discursos das/os alunas/os entrevistadas/os sobre o que caberia a meninos e a meninas. São termos, palavras e associações que representam o jogo das relações de gênero em seu antagonismo e binaridade:

QUADRO 2: REPRESENTAÇÕES DE GÊNERO 1

\begin{tabular}{|l|l|}
\hline \multicolumn{1}{|c|}{ MENINO } & \multicolumn{1}{|c|}{ MENINA } \\
\hline Liberdade & Privação \\
\hline Espaço público & Espaço privado \\
\hline Tarefas domésticas facultativas & Tarefas domésticas obrigatórias \\
\hline Não-comportado & Comportada \\
\hline
\end{tabular}

Fonte: Pesquisa de Campo, 2016.

Essas representações são absorvidas e reproduzidas e constituem o centro nevrálgico do sistema sexo/gênero, no qual as irradiações espelham a binaridade, antagonismo e oposição entre mulheres e homens, que servem para que pensemos como rearticular essas dimensões que estão assentadas em naturalizações e essencializações de toda ordem; é urgente atacarmos teoricamente esses esses dispositivos. 


\section{QUESTÕES DE GÊNERO NA ESCOLA: MODELANDO MENINAS E MENINOS}

Nas falas de nossas/os entrevistadas/os, a escola é vivenciada como um espaço essencial de sociabilidade, uma vez que possuem a liberdade regulada pelos pais, é na escola que tecem as principais relações sociais. Por outro, é possível também perceber que as representações sobre ser menino ou menina que as/os alunas/os possuem são também reproduzidas no ambiente de interação social que é a escola.

Destacamos aqui as falas que dizem respeito a uma ideia que ainda é realidade entre nossas/os alunas/os: a construção de um modelo de comportamento para as meninas-alunas e meninos-alunos; muitas vezes este comportamento é monitorado de perto por algumas/ns professoras/es.

Pesquisadoras/es: Aqui na escola, tu consegues perceber alguma diferença na forma em que os meninos e as meninas são tratados?

Elisa: Como assim, por quem? Pelas/os professoras/es?

Pesquisadoras/es: No geral, na sua sala de aula, por exemplo, os meninos têm tratamento igual a vocês?

Elisa: Ah, tá... não... tem algumas coisas que não.

Pesquisadoras/es: Podes me dar um exemplo?

Elisa: Hum... por exemplo quando tem trabalho em grupo, sempre a gente tem que organizar tudo, e até copiar, porque a letra deles é horrível (risos). Quando tem também alguma coisa que toda a turma tem que fazer... a feira de Humanas, a gente que arrumou e comprou as coisas, eles só desarrumaram depois e carregaram as cadeiras pra sala.

Pesquisadoras/es: E por que vocês não pediram a ajuda deles para a organização?

Elisa: Ah... professora, porque eles não sabem arrumar nada (risos) e também a professora que tava com a gente disse que era melhor só as meninas virem arrumar.

Observamos na fala de Elisa dois estereótipos que ainda persistem: um é a suposta diferença entre as letras de meninas e meninos; aquelas teriam a "letra mais bonita". E, por isso, nos trabalhos em grupo, acabariam assumindo a maior parte da responsabilidade. Outra ideia viria da maior capacidade de organização atribuída às meninas. Estes estereótipos continuam sendo utilizados para justificar a atribuição de maiores responsabilidades para meninas e isentar os meninos de algumas tarefas pertinentes ao âmbito escolar. A reprodução de tais estereótipos, principalmente deste último, extrapola o espaço da escola e em determinados momentos alcançam o ambiente da casa, por exemplo: os meninos não são convidados a realizar atividades que visem manter a organização do ambiente, uma vez que esta capacidade é considerada feminina.

Para dar ênfase a esta ideia, temos um episódio relatado por Nayara, que conta que em determinada ocasião, ao levar seu caderno para que a professora lhe corrigisse a tarefa, recebeu uma advertência: a professora se incomodou com o estado do caderno e com a letra de Nayara. Em contrapartida, o colega com o caderno nas mesmas condições que o dela não sofreu nenhuma advertência. 
Nayara: Ela ficou falando que meu caderno deveria ser mais organizado. E ainda escreveu que eu tinha que escrever melhor. Depois o Luan entregou o dele... a senhora já viu o bacalhau que o Luan chama de caderno, né?! (risos) E ela só corrigiu e nem falou nada.

A organização como característica eminentemente das meninas e a bagunça e desorganização como característica dos meninos foram citadas por todas/os as/os quatro entrevistadas/os. O aluno Robert aponta uma diferença interessante para nossa reflexão ao ser questionado sobre as diferenças entre meninos e meninas na escola e na sua sala de aula.

Robert: Meninas trazem comida e os meninos refrigerantes (risos). Pesquisadoras/es: Por que vocês escolhem trazer os refrigerantes?

Robert: Porque é mais fácil (risos). Mas não é a gente que escolhe não... é só o que sobra pra nós trazer. (risos)

Elisa, quando questionada sobre o fato mencionado por Robert, responde:

Elisa: Eles nunca querem ter trabalho com nada, professora! Sempre escolhem trazer coisas pra beber ou dar dinheiro pra gente comprar; pegam sempre o mais fácil.

Pesquisadoras/es: E porque vocês não tentam inverter: deixem as comidas com eles e tragam o refrigerante?

Elisa: Aí, a gente só vai beber refrigerante porque eles não vão trazer! É certeza, professora!

No entanto, Thiago se demonstra mais otimista sobre essa possibilidade:

Pesquisadoras/es: E ser vocês invertessem: as meninas trouxessem as bebidas e vocês ficassem com a comida?

Thiago: A gente teria que trazer, né, pra não ficar com fome (risos)!

Esta divisão não é estranha para muitas/os de nós, pois ao lembrarmos de nosso cotidiano no espaço escolar seremos capazes de lembrar de pelo menos uma ocasião em que durante a organização da costumeira confraternização de fim de ano da turma tudo pareceu solucionado com um inocente: "as meninas trazem a comida e os meninos trazem refrigerantes". Talvez nunca tenhamos nos questionado o porquê de os pratos de comida serem atribuição das meninas - mesmo sabendo que dependendo da faixa etária da turma, não seria elas a cozinhar -, e porque para os meninos temos tarefas bem mais simples: contribuir financeiramente, trazer os materiais descartáveis ou simplesmente trazer os refrigerantes. Quando normatizamos esta divisão na sala de aula, estamos colaborando para a manutenção da norma social pensada para os gêneros que situa os homens fora do ambiente da cozinha, deixando-o pensar que comprar os refrigerantes já está de bom tamanho.

Estar no ambiente da cozinha, ou fora dele, não é o ponto central da discussão e sim como representamos em termos de gênero esse espaço, quem (não) está nele e o motivo disso acontecer. 
Ou ainda, quem é obrigado a estar nesse ambiente por suposição de que seja o gênero, o feminino, que tenha o perfil para desempenhar as atividades inerentes a ele.

Quando analisamos as respostas das entrevistadas neste caso de organização de festas escolares, concluímos que a normatização dos gêneros é verificada em situações como estas que se impôs, nas quais meninas e meninos têm obrigações distintas, nas quais as tarefas encontram-se divididas pelo gênero; provocando desigualdade em termos de responsabilidade com tarefas que demandam mais trabalho sendo atribuído às meninas.

O papel da escola neste processo de vivência das representações de gênero por parte de meninos e meninas reside na reprodução das normas regulamentadoras de gênero, tudo que é construído socialmente acerca do gênero. A reprodução localiza meninas e meninos em suas instâncias de atuação previamente determinadas. Em consonância à reprodução está a fiscalização e manutenção das normas sociais que regulam o comportamento de meninos e meninas enquadrando a escola na definição de Foucault (2007) como espaço regulatório e de vigilância.

No caso da organização citada, poderia ser feita uma intervenção por parte das/os professoras/es no sentido de questionar as/os alunas/os quanto à possibilidade de uma divisão na organização não mais por gênero, mas por outras variantes, como vizinhança, parentesco e afinidade, por exemplo, possibilitando uma igualdade de oportunidades, independente do gênero.

A escola é formada por gestoras/es, técnicas/os, agentes operacionais e professoras/es, além das/os alunas/os, e todas/os possuem papel fundamental na criação de novas perspectivas no que se refere à desconstrução de paradigmas equivocados. A/O aluna/o está na escola para aprender, conhecer e questionar. Para tanto, é necessário a mediação por parte dessas/es agentes que compõem o espaço escolar. São essas as novas possibilidades ações e ideias difundidas entre todas/os e para todas/os sem perder de vista a função ideal da escola de refletir e incorporar as discussões sociais.

A mediação do conhecimento na área de gênero deve ser bem articulada e direcionada, tendo como base sempre o respeito e a preservação da dignidade humana. Ideias contrárias devem ser combatidas de forma inteligente e moderadas para que não se termine por desrespeitar crenças e convicções.

Nos documentos oficiais, como os Parâmetros Curriculares Nacional para o Ensino Médio (2000), o tema gênero é elencado, levando-nos a crer que o Estado e suas políticas já verificaram a necessidade de ensinar o tema na escola. Contudo, percebemos que as/os professoras/es e corpo técnico da escola ainda não incorporaram a ideia a ponto de se permitirem refletir sobre elas e repassar o conhecimento às/aos alunas/os. O que se percebe muitas vezes são falas de preconceitos e distinções 
entre meninas e meninos que resultam em tratamento desigual. Abaixo, resumimos as contraposições apresentadas, direta ou indiretamente, nas falas das/os alunas/os entrevistadas/os sobre o que cabe aos meninos e às meninas:

\section{QUADRO 3: REPRESENTAÇÕES DE GÊNERO 2}

\begin{tabular}{|l|l|}
\hline \multicolumn{1}{|c|}{ MENINO } & \multicolumn{1}{c|}{ MENINA } \\
\hline Desorganização & Organização \\
\hline Letra feia & Letra bonita \\
\hline Bebidas & Comidas \\
\hline
\end{tabular}

Fonte: Pesquisa de Campo, 2016.

Educar, orientar e fazer pensar sobre este tópico dos Direitos Humanos que são as relações de gênero passam a ser mais uma das funções da educação formal. Essa temática se insere nos contextos das disciplinas e áreas de conhecimentos administradas nas escolas. Este fato surge da necessidade de discutir sobre temas recorrentes da sociedade que resultam na falta de respeito, violência e discriminação. Essa discussão tem por finalidade a conscientização de todas/os pela efetividade dos Direitos Humanos e preservação da dignidade humana.

\section{CONSIDERAÇÕES FINAIS}

A pesquisa forneceu informações que evidenciar o que as/os alunas/os entendem por ser menino ou menina. A representação ou o que significa ser pertencente a um gênero feminino ou masculino, bem como observou como a escola e a família reiteram normas de gênero construída na sociedade e articulada nas interações sociais. Nas falas de nossas/os entrevistadas/os, observamos que as características definidas para meninos/meninas são vivenciadas em casa, com a família, na relação com os pais e irmãos; na escola, na interação com os colegas e toda a comunidade escolar. Observamos, ainda, que as limitações para menino e menina são evidentes e não deixam dúvidas quanto ao fato de que o gênero é um construto social, que encontra respaldado na repetição de atos performativos (BUTLER, 2003).

Por certo, há de se verificar que o que se entende por ser homem ou mulher não é exatamente igual ao que se concebia há décadas; houve uma transformação nos modos de ser e pensar na sociedade ocidental. Como foi dito na introdução deste trabalho, a concepção de gênero modifica-se ao longo do tempo, porém sem desprender-se do entendimento equivocado de que menino/meninas nascem com qualidades, virtudes e defeitos apoiada apenas no sexo ou órgãos genitais. 
Como afirma Bento (2011), desde que se descobre o sexo do bebê em um exame de ultrassom toda uma vida é traçada, cores são definidas - rosa pra meninas, azul para meninos. Pronto. A partir de então, ações e atitudes deverão seguir um rito de permissividade, o que pode ou não pode, o que deve ou não ser feito, dependendo do sexo da criança. O menino vai brincar de carro e a menina de casinha. Inversões não são vistas com bons olhos, nem a ausência das ações previamente traçadas são aceitas, dando margens para suposições de alternância de gênero ou para identidades transgressoras.

Assim, esta criança irá crescer e aprenderá que ser bagunceiro cabe mais aos meninos e não às meninas, reconhecidas como símbolo de passividade e calmaria; que ser da rua é próprio de meninos e ser de casa, das meninas; que os afazeres domésticos pertencem às meninas e aos meninos são permitidas mais horas de folga, sem a necessidade de aprender a cuidar-se, por exemplo.

Os estudos de gênero abarcam também temas como as homossexualidades e demais formas de sentir e amar, por exemplo. No entanto, o foco em gênero traz consigo o entendimento sobre como as culturas reproduzem injustiças e mascaram as habilidades e características de mulheres e homens como um fator congênito (que estaria impresso no gene na hora de sua concepção biológica). $\mathrm{O}$ problema desta concepção equivocada está na geração de hierarquias, levando-nos a crer que o homem é superior à mulher. E, ainda, que a manipulação de condutas precisa existir para fabricarem pessoas validadas pela sociedade; e isso significa que as condutas das pessoas precisam ser orientadas pelo que admitem como correto ou normal; imputando àquelas/es que se desvirtuam pesados fardos de discriminação.

As representações de gênero são aprendidas em casa, com a família, e continuam a serem aprendidas na escola. Tudo muito normal e simples. Contudo, não é para ser normal, visto que o sistema de fabricações de meninos e meninas trazem marcas de desvantagens, privilégios, desigualdades e injustiças. O menino tem o privilégio da liberdade e do pertencimento ao espaço público em comparação à menina. As atividades domésticas são obrigações das meninas e de caráter facultativo para os meninos, o que representa uma injustiça. Na organização das festas escolares, vimos, no que tange à divisão de tarefas, as meninas ficarem encarregadas de trazer a comida, que demanda mais trabalho na elaboração, apresentando desvantagem quanto à responsabilidade dos meninos, que só precisam trazer as bebidas, algo mais simples de se resolver.

Desse modo, com base no estudo realizado, sugerimos medidas: maior empenho por parte da escola em trazer estudos e debates sobre as questões de gênero para o dia a dia da escola; envolvendo a comunidade escolar e conscientizando sobre a importância do respeito aos Direitos Humanos e equidade de gênero. Uma outra medida que sugerimos é o envolvimento da escola com os familiares 
das/os alunas/os, com o intuito de debater as questões de gênero nas reuniões e também na organização de eventos, como palestras e diálogos com especialistas nessa área de estudos. Além destas, há também o oferecimento de cursos de formação continuada para as/os professoras/es na área de Direitos Humanos e nos Estudos de Gênero, afinal nada melhor do que o conhecimento para a construção e consolidação do real entendimento sobre os assuntos que rodeiam as interações sociais que atravessam a escola, sejam elas entre as/os alunas/os ou entre alunas/os e professoras/es e demais agentes do espaço escolar.

Sabemos que este processo não é simples, uma vez que implica abrir-se ao novo e reconhecer as perversas imposições culturais, tendo a lucidez para mudar o que precisa ser mudado, ainda que custe abrir mão de convicções e verdades. Porém, acreditamos que o avanço das décadas nos trouxe outras perspectivas e que já é possível vislumbrar escolas capazes de compreender e ensinar que muitas desigualdades e hierarquias não existem por definição da natureza, mas sim por definição da cultura.

\section{REFERÊNCIAS}

ARIES, Philippe. História social da criança e da família. Rio de Janeiro: Guanabara, 1986.

BEAUVOIR, Simone. O segundo sexo - 2. A experiência vivida. São Paulo: Difusão Europeia do Livro, 1967.

BENTO, Berenice. Na escola se aprende que a diferença faz a diferença. Em: Estudos Feministas, v. 19, n. 2, 2011, p. 549-559. Disponível em https://www.scielo.br/pdf/ref/v19n2/v19n2a16.pdf. Acesso em 24 Dez. 2020.

BUTLER, J. Problemas de gênero: feminismo e subversão da identidade. Rio de janeiro: Civilização Brasileira, 2003.

DAMATTA, Roberto. A casa \& a rua: espaço, cidadania, mulher e morte no Brasil. Rio de Janeiro: Rocco, 1997.

FOUCAULT, Michel. Vigiar e punir: nascimento da prisão. Petrópolis: Vozes, 2007.

GÊNERO NAS ESCOLAS. Produção: Para Tudo. Apresentação: Lorelay Fox. Duração: 4 min. e 56 seg. Disponível em https://www.youtube.com/watch?v=ZIJ2Ifu6SIM. Acesso em 24 Dez. 2020.

LOURO, Guaraci Lopes. Gênero, sexualidade e educação: uma perspectiva pós-estruturalista. Petrópolis, RJ, Vozes, 1997.

NASCIMENTO, Célia Regina Rangel; TRINDADE, Zeide Araújo. Criando Meninos e Meninas: investigação com famílias de um bairro de classe popular. Arquivo brasileiro de psicologia. Vol. 62, n. 2. Rio De Janeiro. 2010. 
PARÂMETROS CURRICULARES NACIONAIS - Ensino Médio. Parte IV. Ciências Humanas e suas tecnologias. Conhecimentos de Antropologia, Sociologia e Política, 2010, p. 37- 45.

PISCITELLI, Adriana. Gênero: a história de um conceito. Em: ALMEIDA, Heloísa Buarque de \& SZWAKO, José Eduardo (Org.). Diferenças, igualdade. São Paulo: Berlendis \& Vertecchia, 2009, p. 116-149.

RUBIN, Gayle. Políticas do sexo. São Paulo: Ubu Editora, 2017.

SCOTT, Joan. Gênero: uma categoria útil para análise histórica. Em: Educação \& Realidade, v. 20, n. $2,1995, \quad$ p. $11-99, \quad 1995 . \quad$ Disponível em https://www.seer.ufrgs.br/educacaoerealidade/article/viewFile/71721/40667. Acesso em 24 Dez. 2020. 
